\title{
Nanoemulsions as Ophthalmic Drug Delivery Systems
}

\section{Oftalmik İlaç Taşıyıcı Sistemler Olarak Nanoemülsiyonlar}

\author{
(D) Rasha Khalid DHAHIR, (D) Amina Mudhafar AL-NIMA*, (D) Fadia Yassir AL-BAZZAZ \\ Department of Pharmaceutics, College of Pharmacy, University of Mosul, Mosul, Iraq
}

\begin{abstract}
Nanoemulsions are liquid-in-liquid dispersion with a droplet size of about $100 \mathrm{~nm}$. They have a transparent appearance, high rate of bioavailability, and increased shelf life. Nanoemulsions mainly consist of oil, water, surfactant, and cosurfactant and can be prepared by high- and low-energy methods. Diluted nanoemulsions are utilized for the delivery of ophthalmic drugs due to their capability to penetrate the deep layers of the ocular structure, provide a sustained release effect, and reduce the frequency of administration and side effects. These nanoemulsions are subjected to certain tests, such as safety, stability, pH profile, rheological studies, and so on. Cationic nanoemulsions are prepared for topical ophthalmic delivery of active ingredients from cationic agents to increase the drug residence time on the ocular surface, reducing their clearance from the ocular surface and improving drug bioavailability. This review article summarizes the main characteristics of nanoemulsions, ophthalmic nanoemulsions, and cationic nanoemulsions and their components, methods of preparation, and the evaluation parameters for ophthalmic nanoemulsions.
\end{abstract}

Key words: Nanoemulsion, cationic nanoemulsions, ophthalmic drug delivery

Öz

Nanoemülsiyonlar, yaklaşık 100 nm'lik bir damlacık boyutuna sahip sıvı içinde sıvı dispersiyonudur. Şeffaf bir görünüme, yüksek biyoyararlanıma ve artırılmış raf ömrüne sahiptirler. Nanoemülsiyonlar esas olarak yağ, su, yüzey aktif madde ve yardımcı yüzey aktif maddeden oluşur ve yüksek ve düșük enerjili yöntemlerle hazırlanabilir. Seyreltilmiș nanoemülsiyonlar, oküler yapının derin katmanlarına nüfuz etme, sürekli salım etkisi sağlama ve uygulama sıklığını ve yan etkileri azaltma kabiliyetleri nedeniyle oftalmik ilaçların verilmesi için kullanılır. Bu nanoemülsiyonlar, güvenlik, stabilite, pH profili, reolojik çalıșmalar vb. gibi belirli testlere tabi tutulur. Katyonik nanoemülsiyonlar, ilacın oküler yüzey üzerinde kalış süresini artırmak, oküler yüzeyden klirensini azaltmak ve ilaç biyoyararlanımını geliştirmek için katyonik ajanlardan aktif bileşenlerin topikal olarak oftalmik taşınımı için hazırlanır. Bu derleme, nanoemülsiyonların, oftalmik nanoemülsiyonların ve katyonik nanoemülsiyonların temel özelliklerini ve bileşenlerini, hazırlama yöntemlerini ve oftalmik nanoemülsiyonlar için değerlendirme parametrelerini özetlemektedir.

Anahtar kelimeler: Nanoemülsiyon, katyonik nanoemülsiyonlar, oftalmik ilaç verilmesi

\section{INTRODUCTION}

Ophthalmic drug delivery system is one of the most important routes of drug administration, but it is regarded as a challenging attempt encountered by pharmaceutical scientists. Most ophthalmic diseases are treated by topical eye drop instillation; however, several problems, such as poor bioavailability, are associated with these formulations. ${ }^{2}$
The drug is removed from the precorneal area within several minutes after instillation due to lacrimal secretion and nasolacrimal drainage. 3,4

Various problems, including the issue on stability, high cost, and tedious preparation methods, are associated with the scalingup of nanoemulsions. ${ }^{5}$ 
For the above reasons, pharmaceutical scientists attempt to formulate ophthalmic preparations that can overcome such problems. Although the incorporation of drugs in different pharmaceutical vehicles, such as ointments, suspensions, and emulsions, can improve the bioavailability and provide sustained drug release, they cannot be regarded as the formulation of choice given their ocular adverse effects, including irritation, redness of the eye, interference with vision, and low product stability. In addition, chronic administration may increase systemic availability and cause severe systemic complications. Formulations containing preservatives also induce adverse reactions upon systemic absorption. 3,6,7

Nanotechnology is one of the most important promising approaches for ophthalmic drug delivery. This technology is currently being applied for drug delivery to the anterior and posterior segments of the eye. Nanotechnology-based systems with an appropriate particle size can be formulated to ensure low irritation to the patient's eye, adequate bioavailability, and compatibility with the ocular tissue. Such systems are an excellent approach for the delivery of lipophilic drugs, which involves the application of cationic nanoemulsion, benefitting from the negatively charged corneal and conjunctival cells that can prolong the drug residence time on the ocular surface and improve drug absorption and bioavailability. ${ }^{8,9}$

\section{Barriers for intraocular drug transport}

Each layer of the ocular tissue has distinct features and poses a diverse barrier following drug administration via a certain route (Figure 1). ${ }^{10}$

\section{Tears}

Tears can influence the administration of ophthalmic drugs through binding with the administered drug, resulting in enhanced clearance and drug dilution. Tear turnover is one of the dynamic barriers that significantly decrease drug availability, leading to inhibition of therapeutic effect. ${ }^{1,11}$

\section{Cornea}

The cornea, which is a non-vascular structure, consists of three main layers: the outer epithelial layer which is a lipophilic layer, the middle stromal layer which is hydrophilic in nature, and the inner endothelial layer that separates the aqueous humour and the stroma. ${ }^{5}$ The corneal epithelium forms the most important barrier to drug absorption by topical administration; the corneal cells of glycosyl amino glycans lining the ocular surface are negatively charged at physiological $\mathrm{pH}^{5,6}$ When applying a positively charged formulation to the eye, an electrostatic

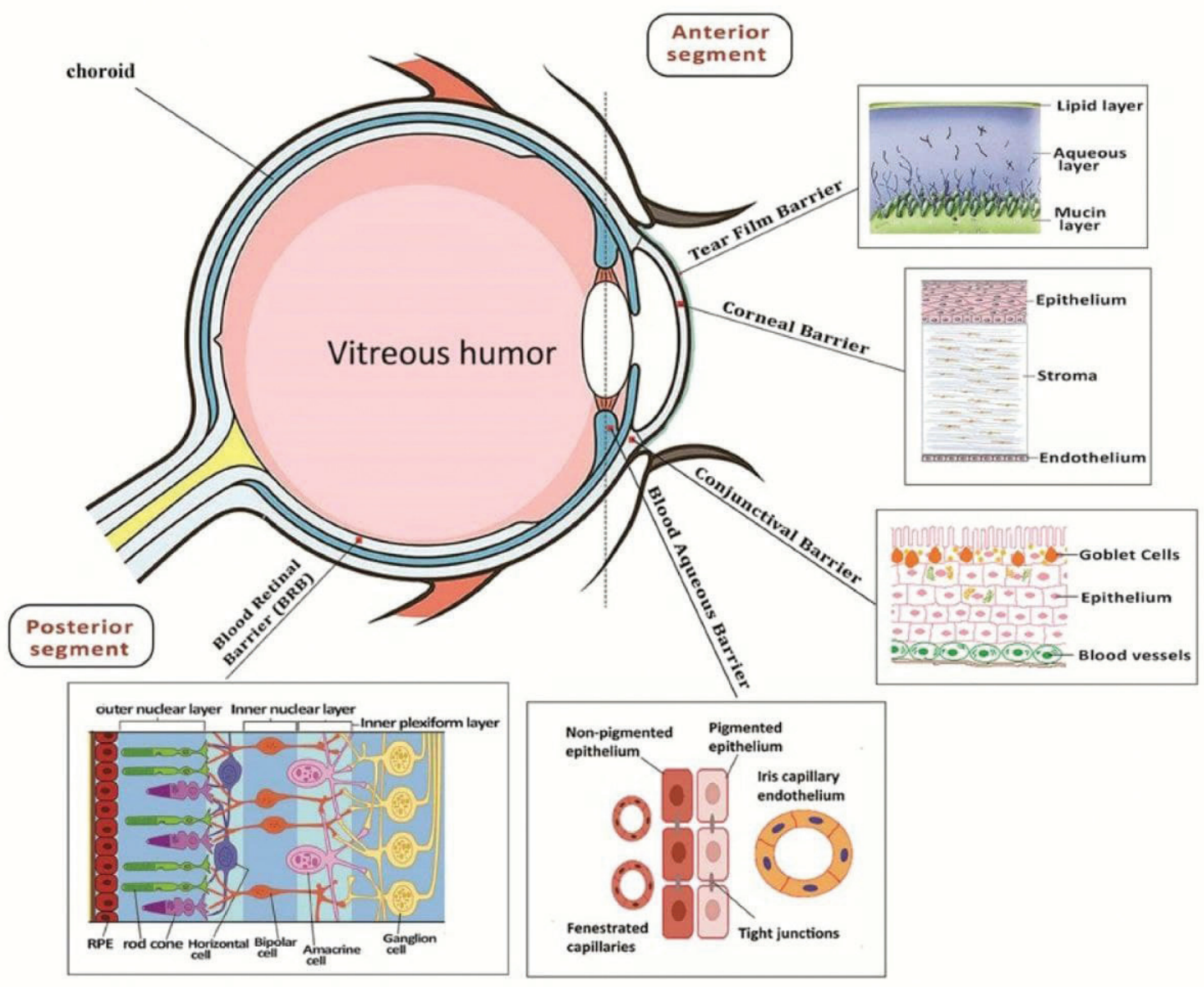

Figure 1. Ocular barriers for drug transport ${ }^{10}$

Permission has been obtained from the author for the use of the figure 
attraction will possibly occur, which will prolong the residence time of the formulation on the ocular surface. 5,12

\section{Conjunctiva}

The conjunctiva of the eye is a thin layer that lines the inside of eyelids and maintains the tear film. The stroma between the outer conjunctival epithelium and inner sclera has an abundance of blood and lymphatic vessels throughout the subconjunctiva, and it acts as a dynamic barrier to hydrophobic drug absorption. Given the rich capillaries and lymphatic vessels in the stroma, the drug administered to the conjunctival sac can be rapidly cleared., 812 The conjunctival epithelium is more penetrable to larger molecules and has 20 times larger surface area than the cornea because of its wider intercellular spaces. The conjunctival pathway favors the absorption of large hydrophilic molecules (with molecular weight nearly less than $20 \mathrm{kDa}$ ), such as proteins and peptides, different from the corneal route which favors lipophilic small molecules (the majority of drugs). Meanwhile, the retardation of the passive pathway can occur by the tight junctions present in the conjunctival epithelium. Therefore, if drug absorption through the conjunctiva is compared with that through the cornea, the former is considered as non-productive, leading to the low bioavailability of ophthalmic drugs. ${ }^{11,12}$

Sclera

The sclera is the outer layer of the eyeball and is known as the white of the eye. This part can maintain the eye shape through its fibrous structure. The hydrophobic nature of drugs affects the permeability of sclera; when the lipophilicity of a drug increases, the permeability across the sclera will decrease, and vice versa. ${ }^{8}$ Moreover, the permeation of therapeutic molecules, including drugs, depends on the hydration degree of sclera and its intraocular pressure. Intraocular pressures in the normal range of $15-20 \mathrm{mmHg}$ have negligible effects on permeability, whereas the trans-scleral permeability of solute molecules is affected by their high intraocular pressure up to (>20-60 $\mathrm{mmHg})^{11}$

\section{Choroid/Bruche's membrane}

This part of the eye is regarded as the most vascularized part of the body. The choroidal thickness decreases with age. By contrast, the thickness of Bruch's membrane increases with age, and the changes in the thickness of choroid and Bruch's membrane may affect drug penetration into the retina. ${ }^{8}$ With aging, the choroid becomes thinner, and the Bruch's membrane becomes thicker, leading to alteration in the barrier property which in turn alters drug permeation of drug molecules over the years. ${ }^{11}$

\section{Retina}

The retina is located at the back of the eye, on which an image is formed from the light that enters the eye from the cornea, passing across the anterior part until it reaches the retina in the posterior part of the eye, where it can then be interpreted in the brain. The retina may be subjected to diseases that affect the posterior segment of the eye, such as age-related macular degeneration and diabetic retinopathy. All of the drugs in the vitreous can be eliminated by anterior and posterior route; the drugs can be eliminated across the retina after passing through the internal limiting membrane that separates the retina and the vitreous. ${ }^{8,9}$

CD44 is over expressed on the retina surface and is important in targeting a number of drugs and gene-based therapeutics.

Table 1. Anatomical barriers for intraocular drug transport ${ }^{13}$

Anatomical barriers Characteristics

Cornea

Epithelium is a major barrier to passage of hydro-philic drugs; tight intercellular junctions restrict

Stroma is a barrier to passage of highly lipophilic drugs.

Tear $\quad$ Drugs bind with mucin, dilution of topical drugs.

Induced lacrimation and tear film turnover increase drug clearance.

Conjunctiva

More permeable than cornea to hydrophilic drugs and macromolecules; has greater surface area. Epithelium-tight intercellular junctions.

\begin{tabular}{ll}
\hline Sclera & $\begin{array}{l}\text { Hydrated stroma better absorption of hydrophilic drugs. } \\
\text { More permeability to macromolecules. } \\
\text { Molecular radius is an important parameter to determine permeation. }\end{array}$ \\
\hline Choroid & $\begin{array}{l}\text { Receives less blood flow, resulting in less drug permeation from the systemic circulation. } \\
\text { Choroid Bruch's membrane limits permeation of lipophilic drugs. }\end{array}$ \\
\hline Vitreous humour & $\begin{array}{l}\text { Hyaluronan- is more permeable to anionic drugs (due to negatively charge). } \\
\text { Large, lipophilic/hydrophilic drugs retained more in vitreous humor. }\end{array}$ \\
\hline Retina & $\begin{array}{l}\text { Permeable to small, lipophilic, or hydrophilic molecules. } \\
\text { Inner limiting membrane limits entry of drugs from vitreous into retina. }\end{array}$ \\
\hline Blood ocular barriers & $\begin{array}{l}\text { Blood aqueous barrier- tight junctions limit entry of solutes into aqueous humour and entry of hydrophilic drugs from } \\
\text { plasma into aqueous humour. } \\
\text { Onner blood retinal barrier- major barrier to hydrophilic drugs. }\end{array}$ \\
\hline
\end{tabular}


Retina demonstrates the presence of 15-20 nm-wide intercellular spaces without tight junctions. As a result, small hydrophilic/lipophilic drugs can permeate the retina. However, large cationic molecules exhibit resistance to permeation in the retina. Inner and outer plexiform layers are major barriers to the diffusion of large molecules in human retina. This condition is supported by observations showing the persistence of hard exudates in hypertensive or diabetic retinopathy for months in the retina because molecules greater than $76 \mathrm{kDa}$ diffuse through the retina very slowly, whereas macromolecules with a molecular weight greater than $150 \mathrm{kDa}$ are arrested by the inner limiting membrane..$^{10-12}$

Table 1 presents all the above barriers and their characteristics. ${ }^{13}$ Main challenges and key considerations in ocular drug delivery

\section{Challenges}

The eye is a unique organ anatomically and physiologically, and it contains highly varied structures with independent physiological functions. This complexity of the eye provides special challenges to ocular drug delivery strategies. ${ }^{13}$ One of the challenges is the absorption; as with traditional eye drops, ocular bioavailability after topical administration is low at $3 \%$ $4 \%$ due to the eye's impermeable nature and small surface area. Other challenges include poor drug solubility. Lipophilic drugs cannot be incorporated in conventional aqueous eye drops. For this reason, they must be formulated as suspensions. Regarding patient compliance, frequent instillations are usually needed with eye drops to reach the desired therapeutic range of the drug. High tolerability or comfort demands limit the formulation options. As for excipient choice, limited numbers of expedients are listed in ophthalmology. Finally, the delivery of conventional eye drops to the posterior segment of the eye is impossible.,9

\section{Considerations}

Ocular drugs typically achieve $<10 \%$ ocular bioavailability. If a drug is applied to the outer surface of the eye, it may pass ocular blood barriers where it will encounter metabolizing enzymes and cellular transporters before it reaches the site of action. Thus, the anatomy and physiology of the eye, including the mucus layer, eyelids, metabolism, and blink drainage, must be considered. Other considerations include tear composition, such as enzymes, lipid outer layer, and stability of the tear film; disease state and occurrence of keratitis or inflammation on absorption, drug clearance, and ocular comfort and tolerability of the formulation, including viscosity, drop size, $\mathrm{pH}$, and osmolality. In addition to the above considerations, patient anticipation, squeeze capability, and type of packaging must be accounted for. $8,9,14$

\section{Efflux transporters and ophthalmic drug bioavailability}

The primary barriers result in poor absorption of the drug and poor bioavailability, especially for anterior segment ophthalmic drug delivery. Several of these barriers have been identified in epithelial cells of various ocular tissues in humans and rabbits; these barriers include p-glycoprotein (also called multidrug resistance protein 1), multidrug resistance-associated proteins (MRP1, MRP2, MRP3, MRP4, MRP5, MRP6, MRP7, MRP8, and MRP9), lung resistance proteins, and breast cancer resistance proteins. Current studies focus on the role of these barriers in ophthalmic drug delivery. ${ }^{15,16}$ Efflux transporters for anticancer drugs, antibiotics (ofloxacin and erythromycin), and steroids are recognized and limit drug bioavailability. ${ }^{14}$ However, different studies suggest various concepts, such as the conjugation of drugs to the dendrimer to enable the bypassing of efflux transporters, resulting in an increased drug solubility and therefore increased drug bioavailability. In a study, propranolol (a calcium channel blocker), a well-known substrate of the p-glycoprotein efflux transporter, was conjugated to lauroyl-G3 dendrimers. This conjugation showed enhanced drug solubility. ${ }^{17}$ However, the oral application of dendrimers for drug delivery is in its infancy but may emerge as a promising strategy in the future. ${ }^{18}$

\section{Definition of nanoemulsion}

Nanoemulsions can be defined as a clear and stable dispersion of oil and water. They are mainly composed of the internal, dispersed, and external phases or the dispersion medium. The surfactant and cosurfactant molecules play an effective role in the formation of nanoemulsions due to their capability to reduce the interfacial tension and create a small particle size due to their function in the formation of stable preparations as a result of the repulsive electrostatic interaction and steric hindrance. In general, surfactants are molecules that have a bipolar structure composed of hydrophilic and hydrophobic parts. ${ }^{8,19}$

Nanoemulsions are colloidal carriers of drug molecules with a droplet size in the range of 500-1000 nm (preferably from 100 $\mathrm{nm}$ to $500 \mathrm{~nm}$ ). As a drug delivery system, they increase the therapeutic efficacy and minimize the adverse effects and toxic reactions of the administered drug. ${ }^{20,21}$

Nanoemulsions can be distinguished from microemulsions in terms of their droplet size and physical stability characteristics. Microemulsions are isotropic and transparent systems that contain spherical droplets of the water or oil phase (diameter range: 10-100 nm) and dispersed in an external oil or water phase, respectively. Microemulsions are thermodynamically more stable than nanoemulsions given the necessity of introducing thermal and/or mechanical energy in the preparation of nanoemulsions (i.e., mixing and heating) and phase separation after a certain period after the preparation of nanoemulsions. This condition is one of the most distinctive differences between microemulsions and nanoemulsions in terms of stability. ${ }^{20,22}$

The preparation of nanoemulsion can be classified into two main classes, namely, high-energy methods such as highpressure homogenization and ultrasonication, and low-energy methods such as phase inversion. ${ }^{23}$

The translucent appearance of nanoemulsions is due to a droplet size of less than $100 \mathrm{~nm}$. With such a small droplet size, the nanoemulsion is thermodynamically unstable during dispersion. The required high-concentration of surfactants results in the sticky texture of the formulation. A yellowish appearance and rancid odor occur after storage due to the presence of phospholipids, which are generally used to stabilize nanoemulsions. Thus, a formulation was developed and 
presented to overcome these problems (US6335022b1); this formulation utilizes oxyethylenated and non-oxyethylenated sorbitan fatty esters as surfactants. ${ }^{16}$ The contrivers believed that the use of surfactants selected from oxyethylated or nonoxyethylated sorbitan fatty esters with a molecular weight of more than $400 \mathrm{~g}$ per mole, which are solid at a temperature of less than $45^{\circ} \mathrm{C}$, can result in a stable formulation. In addition, a similar formulation-stabilizing effect can result from amphiphilic lipids from a group of alkaline salts of cholesterol; these formulations can be used as effective delivery vehicles for antiglaucoma, anti-inflammatory, antiviral, and antiallergic effects. $^{23,24}$

The bioavailability of ophthalmic preparations can be improved by enhancing the drug residence time on the cornea through increasing the viscosity of formulations. This effect can be achieved by increasing the fraction of the dispersed oil phase and by incorporating water-soluble polymers, which can form a gel with the continuous aqueous phase. Certain studies demonstrated that caution should be recommended in considering the ideal concentration of water-soluble polymers to obtain the required viscosity with a transparency of the preparation. ${ }^{25}$

Prostaglandins affect a wide range of physiological activities, such as blood pressure, pain awareness, and clotting mechanisms. Several of these analogs are utilized in ophthalmic antiglaucoma preparations, such as travoprost, latanoprost, and bimatoprost. However, such analogs are chemically unstable in aqueous preparations and have a poor water solubility.

Thus, various strategies have been suggested to avoid these challenges. These strategies include $\mathrm{pH}$ adjustment and complexation with cyclodextrin to improve solubility and stability. Solubility can also be improved by the addition of benzalkonium chlorides. The problem associated with these preparations is the ocular intolerability associated with the positively charged resultant preparation. Carli et al. ${ }^{26}$ discovered that neutral zeta potential and non-toxic preparations can be obtained from a nanoemulsion formulation that consists of prostaglandin containing oil phase as an internal phase and is dispersed in the aqueous external phase, utilizing two or more non-ionic surfactants. ${ }^{27}$ Cyclosporin $A$ is used widely for the treatment of dry eye disease. However, precipitation of the drug occurs as a result of its poor solubility in the aqueous medium. In patent disclosures US4649047 and US6582718, the improved formulation of this drug has been reported. ${ }^{28}$

Positively charged ophthalmic preparation strategy is applied by utilizing the negative charge of corneal barriers. United States patent no. 6007826 describes an oil/water preparation consisting of surfactants/lipid; this preparation has a positively charged polar group, resulting in a cationic preparation that can bind strongly to the corneal surface. ${ }^{29}$

Wang et al. ${ }^{30}$ and colleagues from Hainan University, China developed coconut oil-in-water emulsions that were formulated using three polysaccharides. The main effects of the ratio of compounded polysaccharides on their apparent viscosity and interfacial activity were studied. Various data, in addition to the physical stability of the formulated emulsions with different compound polysaccharides, were studied. The results showed that emulsions formulated with compound polysaccharides manifested small average particle sizes, and the stability analysis showed that the emulsion formulated by compounding polysaccharides had preferable physical stability. ${ }^{30}$

\section{Components of nanoemulsions}

The prime components of nanoemulsions are oil, aqueous phase, and emulsifying agents. Different types of oils, such as medium-chain triglycerides, mineral oils, and vegetal oils including castor oil, can be used in ophthalmic nanoemulsions. ${ }^{31}$ Emulsifying agents are important in maintaining product stability because without these agents, the oil and water phases will separate into two layers. These compounds may be surfactants, such as polysorbates, cremophors, poloxamers, tyloxapol, and vitamin E-TPGS. Emulsifying agents should have certain properties, including compatibility with the product and non-toxicity. ${ }^{5,21}$

\section{Desirable properties of emulsifying agents ${ }^{21,32,33}$}

1. They should have the capability to reduce the surface tension to less than 10 dyne/cm.

2. They should form a stable and coherent film around the dispersed phase globules to prevent coalescence.

3. They should provide adequate viscosity and zeta potential for optimum stability.

4. They should be effective in low concentration.

Types of films around dispersed globules in nanoemulsions ${ }^{34,35}$

\section{Monomolecular film}

The surfactants that stabilize nanoemulsions form a monolayer of ions or adsorbed molecules at the interface, and this monolayer reduces the interfacial tension; to date, a combination of emulsifying agents can be used; such a combination is composed of a hydrophilic emulsifying agent at the aqueous layer and lipophilic one at the lipoid layer to produce a complex film at the interface. ${ }^{36}$

\section{Multimolecular film}

A multimolecular film around the droplets is formed by hydrated lyophilic colloids; these agents do not lower the surface tension significantly but can increase emulsion stability through their tendency to enhance the viscosity of the external phase. ${ }^{34}$

\section{Solid particulate film}

This type of film is produced by emulsifying agents, which are small solid particles and form a film around the dispersed droplets, hence inhibiting their coalescence. ${ }^{34,35}$

\section{Preparation of nanoemulsions}

Two main methods are used for nanoemulsion preparation: High-energy and low-energy methods. Low-energy methods involve changing the composition or temperature, which results in system reversal and the formation of small droplets. The most common low-energy methods are emulsion inversion point (EIP) and phase inversion temperature (PIT) methods. ${ }^{32,37}$ 
High-energy methods consist of two main steps, which result in the formation of the nanoemulsion. The first step involves the mixing of oil, water, and surfactant for a sufficient period in a simple stirrer system, resulting in the formation of oil/water macroemulsion. The second step includes the conversion of the macroemulsion into a nanoemulsion through a homogenizer, which forces the macroemulsion through a narrow gap; this homogenization is repeated several times until a constant droplet size is achieved (Figure 2a). 22,31,38 Zhang et al. ${ }^{39}$ prepared tacrolimus-loaded cationic nanoemulsions by using a highpressure homogenization method. Meanwhile, Dukovski et $a .^{40}$ used a microfluidizer and homogenizer to prepare an ibuprofenloaded cationic nanoemulsion.

Different from high-energy methods, low-energy methods start with a water/oil emulsion, which is converted into an oil/water emulsion due to the changes in temperature and composition. The EIP method involves the conversion of a water/oil macroemulsion, which is formed initially at room temperature, into an oil/water nanoemulsion through gradual dilution until it passes over the inversion point, at which transformation occurs. This method requires no energy to form the emulsion owing to the low interfacial tension between the oil and water interface, which results in the formation of small droplets. In the PIT method, the initial water/oil macroemulsion is formed at a temperature higher than the PIT, and conversion occurs after cooling to produce the required oil/water emulsion without the need for energy (Figure 2b). 31,41,42 Figure 2 was used with the personal permission from Gupta et al. ${ }^{31}$

\section{Instability of nanoemulsions ${ }^{9,21}$}

1. Flocculation can be defined as an aggregation of small globules to form large floccules.

2. Creaming refers to the settling down or rising up of floccules, which form a concentrated layer. Upon agitation, the emulsion can be reconstituted.

3. Cracking is the permanent instability of a nanoemulsion, in which the internal phase separates as a layer. In this case, upon agitation, the emulsion cannot be reconstituted, and additional amounts of surfactants may be beneficial.

(a) high energy methods

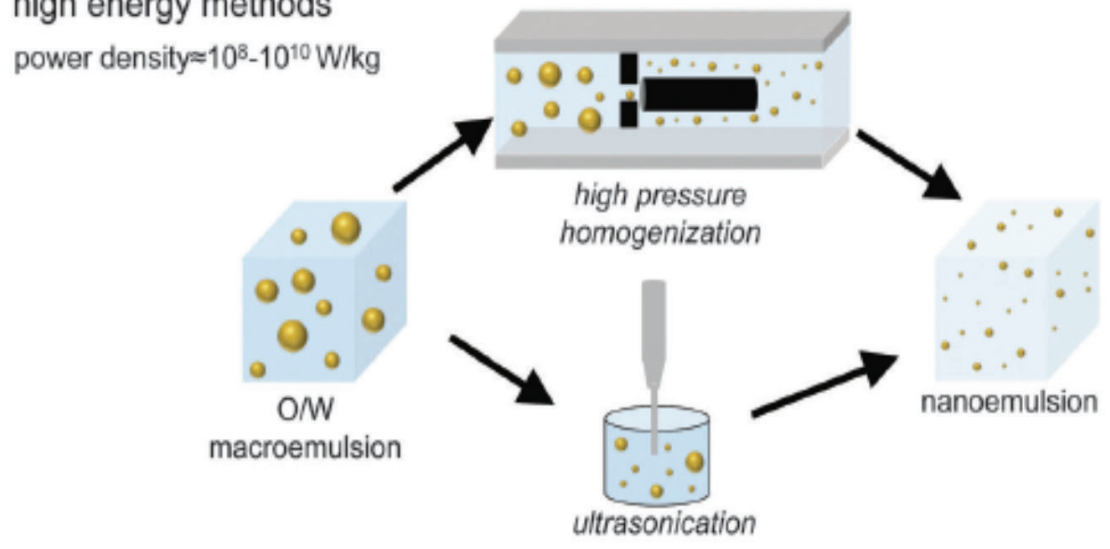

Figure 2a. Overview of high-energy methods, such as high-pressure homogenization and ultrasonication, for the preparation of oil/water nanoemulsion ${ }^{31}$
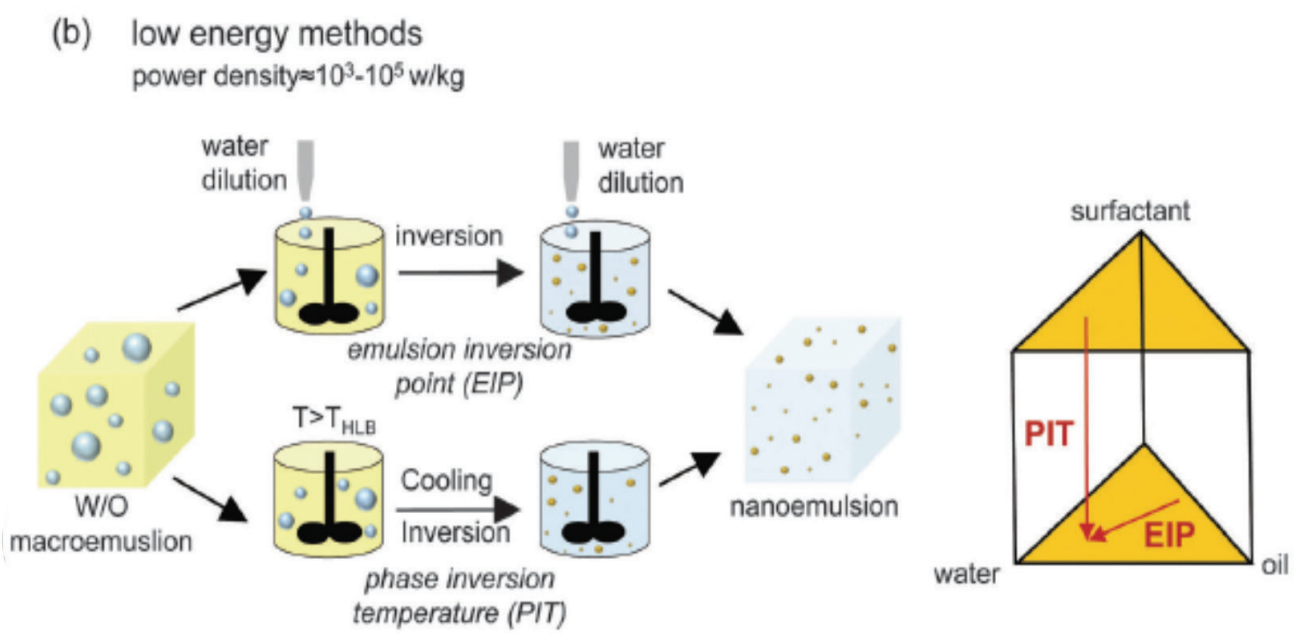

Figure $2 \mathrm{~b}$. Overview of low-energy methods for the preparation of oil/water nanoemulsion

Other nanoemulsion preparation methods, such as as bubble bursting, evaporative ripening, and microfluidization, are also employed ${ }^{31}$ 
4. Miscellaneous instability denotes the instability of a nanoemulsion due to extreme temperature and light. In this scenario, the emulsion should be stored in a tight-colored container.

5. Phase inversion occurs as a result of changes in the volume ratio of phases or addition of electrolytes, which lead to the changes in the emulsion type from water/oil to oil/water, and vice versa.

Important factors during the preparation of nanoemulsions ${ }^{7-9,34}$ One of the most important factor during nanoemulsion preparation is the careful choice of surfactants to achieve an extremely low interfacial tension. The concentration of surfactants must be sufficiently high to stabilize the microdroplets to yield the nanoemulsion. In addition to the above factors, adequate flexibility and fluidity of surfactants should be considered to support the formation of nanoemulsions.

\section{Advantages of nanoemulsions ${ }^{34,35}$}

Nanoemulsions enhance drug bioavailability, are non-irritant, non-toxic, and physically stable, and improve drug absorption due to their high surface area and small droplets size. Nanoemulsions can also be formulated in different formulations, dissolve lipophilic drugs, require less amount of energy, and promote taste masking.

\section{Disadvantages of nanoemulsions ${ }^{34,36}$}

Nanoemulsions require the addition of large amounts of surfactants and cosurfactants to maintain their stability; they have a limited capacity to solubilize high-melting-point substances. In addition, the toxicity of surfactants should be considered, and different environmental parameters can affect nanoemulsion stability. Table 2 summarizes the advantages and disadvantages of nanoemulsions and several of their physical properties.

\section{Cationic oil-in-water nanoemulsion}

Cationic nanoemulsions are preparations that utilize cationic surfactants, which concentrate around the surface of oil droplets to make them positively charged. Owing to the negative nature of the ocular surface, cationic nanoemulsions can improve the residence period of the product in the eye through the electrostatic interaction with the opposite charges of the eye surface mucus layer. Therefore, cationic nanoemulsions probably improve therapeutic efficacy due to an increase in the retention time at the ocular surface. ${ }^{25,43}$ Cationic surfactants should have an adequate lipophilicity to be taken in by oil droplets, with a very small amount present in the aqueous phase. These preparations show an important role in prolonging the residence time of drugs on the ocular tissue, which is greater than that observed in anionic oil/ water nanoemulsions. In addition to their important biological effects, cationic surfactants can stabilize nanoemulsions and prolong their shelf life through preventing the coalescence of oil droplets (Figure 3 ) due to their repulsive force. ${ }^{44,45}$ Table 3 summarizes several important physicochemical features of a cationic oil/water nanoemulsion.

The reason behind the discovery of these cationic nanoemulsions is that different attempts that had been made to extend drug residence time at the ocular surface; the use of excipients with bioadhesive and viscosity enhancement properties, such as cellulose derivatives and propylene glycol, are associated with problems, including ocular disturbance; excipients are only applicable to hydrophilic drugs; in addition, many lipophilic drugs formulated as topical ocular oily or micellar solutions, ointments, and creams are not only uncomfortable to the patient but also show restricted efficacy. ${ }^{46}$

Protective properties of cationic oil-in-water nanoemulsion vehicle

Regarding lipophilic drugs, the application of cationic nanoemulsions to increase ocular bioavailability through prolonging the drug residence time and spreading properties is accompanied by surprising valuable effects on the ocular surface. ${ }^{47}$

By mixing the oil phase in cationic oil/water nanoemulsions with the lipid layer of the tear film, water evaporation from the

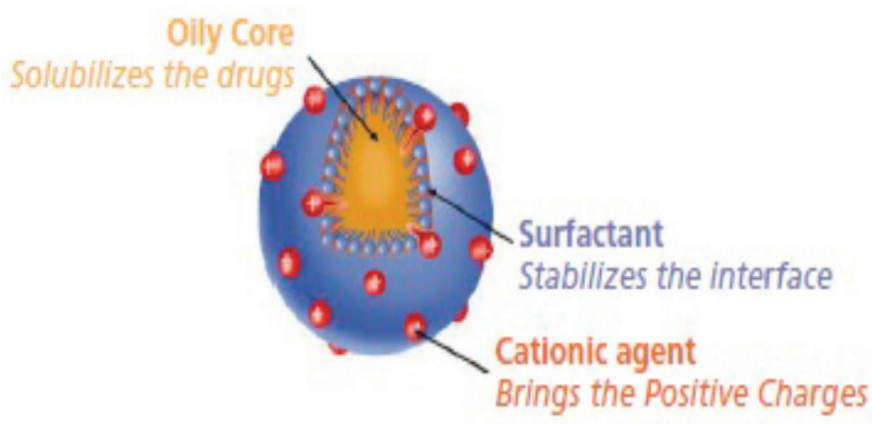

Figure 3. Schematic of one of the oil nanodroplets present in the cationic oil-in-water nanoemulsion ${ }^{50}$

Table 2. Advantages, disadvantages, and several properties of nanoemulsions

\begin{tabular}{lll} 
Advantages & Disadvantages & Other properties \\
\hline Carrier of hydrophobic drugs & Requires large amount of surfactant and cosurfactant & Translucent/translucent system \\
\hline Improves bioavailability of drugs & Low capability to solubilize high-melting-point drugs & High surface area/small droplet size \\
\hline Good shelf stability & Low stability especially in acidic condition & Liquid morphology \\
\hline Toxicologically safe & Toxicity of surfactants and cosufractants is possible & Has benefit to mask taste \\
\hline
\end{tabular}


Table 3. Summary of the physicochemical characteristics of a cationic oil-in-water nanoemulsion ${ }^{50}$

\begin{tabular}{ll} 
Parameter & Description \\
\hline Aspect & White opaque to slightly translucent \\
\hline $\mathrm{pH}$ & $5.0-7.0$ \\
\hline Osmolality $(\mathrm{mOsmol} / \mathrm{kg})$ & 270 \\
\hline Droplet size $(\mathrm{nm})$ & $<200$ \\
\hline Zeta potential $(\mathrm{Mv})$ & Positive $(+40)$ \\
\hline Sterility & Sterile \\
\hline
\end{tabular}

aqueous phase is reduced, which can promote the restoration of the lacrimal film integrity and maintenance of product stability. Such benefits are important for patients suffering from short tear-film breakup time due to lipid deficiency in their tears (meibomian disease). Nanoemulsions are also important in the treatment of keratitis and in the reduction of dry eye disease symptoms by their capability to mechanically stabilize the tear film and increase the hypo-osmolarity of the aqueous film given that hyperosmolarity is a proinflammatory factor. In addition, these preparations have unexpected beneficial effects in the wound healing process by reducing the size of the scraped area. ${ }^{48,49}$

\section{Choice of cationic agent}

A high zeta potential of nanoemulsions is one of the most important factors to be considered before selecting a cationic agent. The entire cationic agent must be trapped in oil nanodroplets, with the positive charge positioned at the oilwater interface, to obtain a high zeta potential; a very small amount of these agents may exist in the aqueous phase, therefore requiring a high-lipophilicity cationic agent. ${ }^{49}$

The selection of cationic agent must be limited to those that have been previously registered, used in ophthalmic products, or submitted to the United States or European pharmacopoeia. Given the large numbers of cationic agents, such as stearylamine, oleylamine, polyethylenimine, polylysine, and benzalkonium chloride derivatives, not all of them can be selected due to their related toxicity. ${ }^{49,50}$ Figure 4 (presented with personal permission from Jean-Sébastien Garrigue) shows a drawing of the phase spreading of diverse alkyl derivatives of benzalkonium chloride in (a) emulsion and (b) aqueous solution. ${ }^{50}$

Stearylamine is one of the most commonly used cationic agents. However, this primary amine is very reactive to various excipients. Thus, this compound is not described in pharmacopoeias. Oleylamine is a cationic lipid that has been used for manufacturing ophthalmic nanoemulsions; however, it has as stability problem owing to the existence of unsaturated sites in the aliphatic chain and the function of its primary amine. ${ }^{49,51}$

Additional cationic molecules that are used for DNA transfection, such as polyethylimine and poly-L-lysine, are

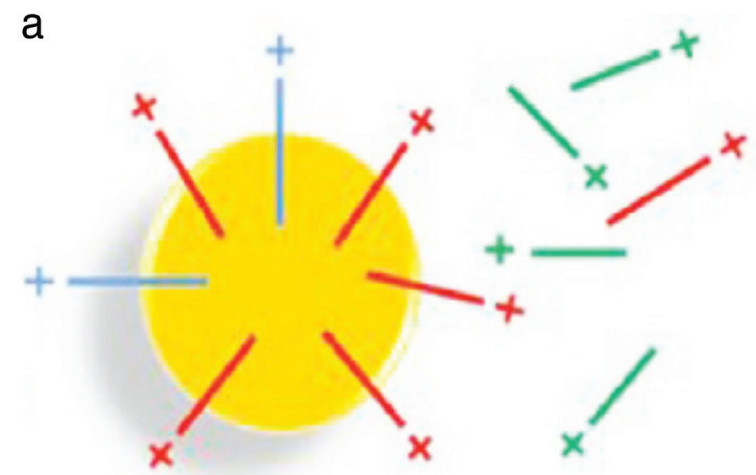

Benzalkonium chloride in emulsion

b

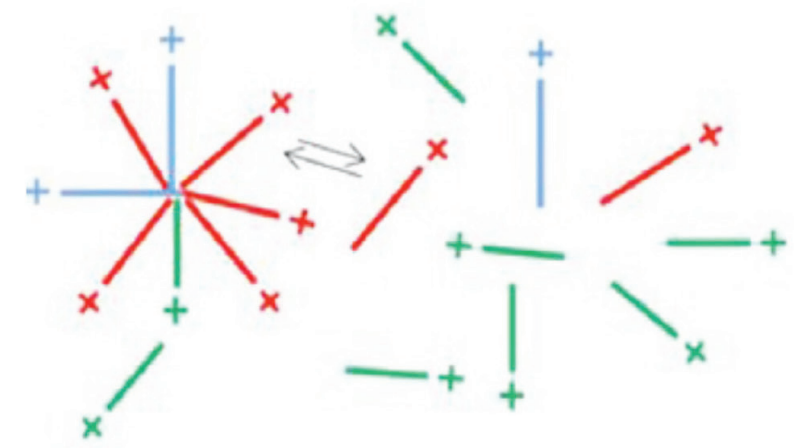

Benzalkonium chloride in solution

Figure 4. Illustration of the phase distribution for the different alkyl derivatives of benzalkonium chloride in (a) emulsion and (b) aqueous solution ${ }^{50}$

also used for cationic drug delivery systems; they are used in various nanoparticles as cationic agents, but several authors regard them as extremely toxic. ${ }^{52}$

Quaternary ammonium compounds, such as benzalkonium chloride, benzododecinium bromide, and cetrimide, are preservatives that have surfactant properties and provide nanoemulsions with a positive charge. Their preservative action is due to their capability to bind negatively charged bacteria and mycoplasma, which destroys their membrane. As a result, 
their action is not only limited to microorganisms but also the epithelial cell lining of the ocular surface via an identical mechanism; in addition, the preservative action of these agents is neutralized by the emulsion because less amount of these agents is present freely in the aqueous medium, which limits their antimicrobial action and results in a toxic effect. ${ }^{53}$

\section{EVALUATION OF OPHTHALMIC NANOEMULSION}

Parameters for evaluation

\section{Zeta potential}

Zeta potential is the measurement of charge repulsion among oil nanodroplets. This variable is one of the most important parameters affecting the dispersed system stability. A high zeta potential results in a stable nanoemulsion. Its value depends on the differences between the electrical potential of the dispersion medium and the stationary layer of fluid close to the dispersed oil nanodroplets. ${ }^{50,54}$

The optimum zeta potential range is between $+20 \mathrm{mV}$ and +40 $\mathrm{mV} .5$

\section{Refractive index}

The refractive index can be determined by using an Abbes refractometer. This index is used to determine any probable impairment of vision or distress after the administration of an eye drop. ${ }^{50,55}$ The refractive index for the tear fluid is 1.340 to 1.360. Eye drops must have refractive index values not higher than $1.476 .^{56}$

\section{Percentage transmittance}

The percentage transmittance can be measured by a spectrophotometer ${ }^{50,54}$ at a specific wavelength with distilled water as a blank. The formulated nanoemulsion is considered transparent if the percentage transmittance is more than $99 \% .^{57}$

pH

The $\mathrm{pH}$ can be measured by using a $\mathrm{pH}$ meter, and the $\mathrm{pH}$ of nanoemulsions should be about $7.2 \pm 0.2$ for maximum comfort. When the $\mathrm{pH}$ of the instilled solution is different from the tear $\mathrm{pH}$, it results in discomfort and irritant effect, which depends on the contact period with the eye surface, solution composition, volume instilled, and buffering capacity. However, in most cases in which the preparation is not buffered or only slightly buffered, a nanoemulsion with a different $\mathrm{pH}$ can be tolerated because the tear $\mathrm{pH}$ can be adjusted to physiological levels; the accepted $\mathrm{pH}$ of preparations is between $3.5-8.5 .^{58,59}$

\section{Surface tension}

The tear film becomes damaged when the surface tension of eye drops is greatly lower than that of the lachrymal fluid (40$50 \mathrm{mN} / \mathrm{m})^{60}$

\section{Rheological measurement}

The influence of an ophthalmic preparation on the normal tear behavior should be as minimal as possible; a less viscous preparation allows limited blinking pain and good tolerance, whereas a more viscous one can improve the residence time of the drug and ocular bioavailability; the viscosity of eye drops should not be more than $20 \mathrm{mPa}$ s. $^{60,61}$

\section{Osmolality}

The lacrimal fluid osmolality is between $280-293 \mathrm{mOsm} / \mathrm{kg}$. However, when the eye is opened, the osmolality is between 231-446 $\mathrm{mOsm} / \mathrm{kg}$ due to evaporation. When the osmolality of a solution is less than 100 or greater than $640 \mathrm{mOsm} / \mathrm{kg}$, the preparation will irritate the eye. However, the osmolality is reestablished 1-2 min after the instillation of a non-isotonic solution. ${ }^{62}$

\section{Ocular irritation study}

These studies should ensure that corneal integrity and structure are not affected. ${ }^{62,63}$

\section{Thermodynamic stability studies}

These studies involve subjecting the nanoemulsion formulation to six cycles between $4^{\circ} \mathrm{C}$ and $45^{\circ} \mathrm{C}$. Then, the stable formulations are exposed to centrifugation test at about 3500 rpm; formulations that do not display phase separation will be obtained for the freeze-thaw stress test; during this test, the formulation is exposed to three freeze-thaw cycles under standard laboratory conditions. .6,64 $^{56}$

\section{Analysis of droplet size}

The droplet size is measured using a diffusion method, a particle size analyzer, light scattering, and LS 230. In addition, droplet sizes can be measured via correlation spectroscopy and transmission electron microscopy. ${ }^{65}$

\section{Viscosity measurement}

Viscosity can be determined by using a rotary viscometer at different temperatures. ${ }^{54}$

\section{Dilution test}

This test ensures that the stability of an ophthalmic nanoemulsion remains unchanged its after dilution; it involves the addition of the aqueous phase to the nanoemulsion without showing any problem. ${ }^{54}$

\section{Drug content}

A predetermined weight of nanoemulsion is extracted by dissolving it in an appropriate solvent, which is then investigated using a spectrophotometer or high-performance liquid chromatograph. ${ }^{54}$

\section{Polydispersity}

This test is performed to determine the droplet size uniformity using a spectrophotometer; the greater the polydispersity, the lesser the uniformity of droplet size. ${ }^{54}$

\section{Cytotoxicity test}

This test examines the effects of a preparation on a certain culture of mammalian cells. ${ }^{66,67}$ 


\section{Examples of ophthalmic nanoemulsion studies and new products}

Nanoemulsions are promising for ophthalmic disease treatment. Thus, diverse studies cover the use of nanoemulsions as ophthalmic drug delivery vehicles, as summarized in Table 4. When formulated as nanoemulsions, drugs, such as timolol, dexamethasone, indomethacin, levobunolol, pilocarpine, and chloramphenicol, exhibit preferred advantages over other traditional formulations (Table 4). Moreover, a number of nanoemulsion products are available either on the market, such as Restasis ${ }^{\circledR}$ (Allergan company) which is used as a nanoemulsion formulation for dry eye disease, or in clinical trials (brimonidine tartrate eye drops for dry eye disease under phase III). All these new examples are shown in Table 5. ${ }^{68,69}$

\section{CONCLUSION}

Owing to the innovation of nanoformulations, which is preferred over the systemic route, a significant improvement has been achieved in ocular disease therapy. Heating and/or mixing must be used in the preparation of nanoemulsions, whereas phase separation may occur after preparation. Thus, nanoemulsions are thermodynamically less stable than microemulsions.

The translucent appearance of nanoemulsions is due to a droplet size of less than $100 \mathrm{~nm}$. As a result of this small droplet size, nanoemulsions exist as thermodynamically unstable dispersion. A high concentration of surfactants is required, resulting in the sticky texture of the formulation. A yellowish appearance and rancid odor occur after storage due to the presence of phospholipids, which are generally used to stabilize nanoemulsions. Nanoemulsions are easily manufactured system prepared by methods which may or may not rely on energy.

Unlike traditional ocular solutions and suspensions, which have considerable bioavailability and require frequent dosing, nanoemulsions have huge potential in enhancing bioavailability and reducing the frequency of drug administration. Surfactants

Table 4. Studies of several ophthalmic nanoemulsion formulations with types of surfactants and cosurfactants and oil used ${ }^{68}$

\begin{tabular}{|c|c|c|c|c|}
\hline S. no. & Drug & Surfactants and co-surfactants & Oil & Comment \\
\hline 1 & Timolol & Lecithin & Isopropyl myristate & $\begin{array}{l}\text { Nanoemulsion bioavailability in aqueous } \\
\text { humour was } 3.5 \text { times more than Timolol } \\
\text { alone. }\end{array}$ \\
\hline
\end{tabular}

2 Dexamethasone Cremophor EL, ropyleneglycol, Isopropyl myristate

Enhanced ocular bioavailability (about three

form) and sustained effect of drug without
ocular irritation.

\section{$3 \quad$ Indomethacin Phospholipids miranol-MHT MCT}

Significant increase in corneal permeability compared with the marketed formulation $\begin{array}{lll}\text { Indomethacin } & \text { MCT } & \text { (Indocollyre }{ }^{\circledR} \text { ) and showed almost } 4 \text { times } \\ \text { corneal permeability coefficient without }\end{array}$ toxicity in ex vivo studies.

\begin{tabular}{|c|c|c|c|c|}
\hline 4 & Levobunolol & Lecithin, glycerol & Soybean oil & $\begin{array}{l}\text { Improved in vitro permeability with a reservoir } \\
\text { effect. }\end{array}$ \\
\hline 5 & Pilocarpine & $\begin{array}{l}\text { Macrogol 1500- } \\
\text { glyceroltriricinoleate, } \\
\text { 6PEG 200, propylene glycol, }\end{array}$ & Isopropyl myristate & $\begin{array}{l}\text { Enhanced ocular bioavailability of up to } 1.68 \\
\text { times with sustained effect and no ocular } \\
\text { toxicity in comparison with aqueous solutions. }\end{array}$ \\
\hline 6 & Chloramphenicol & $\begin{array}{l}\text { Span20, Span80, } \\
\text { Tween20, Tween80 }\end{array}$ & $\begin{array}{l}\text { Isopropyl palmitate and } \\
\text { isopropyl } \\
\text { myristate }\end{array}$ & $\begin{array}{l}\text { Improved stability in nanoemulsion formulation } \\
\text { in comparison to conventional system } \\
\text { as chloramphenicol is relatively prone to } \\
\text { degradation in conventional dosage form. }\end{array}$ \\
\hline
\end{tabular}

Table 5. Ophthalmic nanoemulsions products ${ }^{69}$

Nanoemulsions in the market for ophthalmic disease treatment

\begin{tabular}{|c|c|c|c|c|}
\hline Trade name & Drugs & Formulation & Disease & Company \\
\hline Cyclokat $^{\circledR}$ & $0.1 \%$ cyclosporin A & Cationic nanoemulsion & Dry eye disease & Santen pharmaceuticals \\
\hline \multicolumn{5}{|c|}{ Nanoemulsion under clinical trials for ophthalmic disease treatment } \\
\hline Products & Administration method & Disease & Trial & Phase \\
\hline
\end{tabular}


and cosurfactants are important constituents of nanoemulsions and should be carefully selected. Their concentrations should be high enough to obtain ultra-low interfacial tension.

However, their toxicity presents a concern. In addition, cationic surfactants can be utilized to increase the product residence time on the eye. Accordingly, the use of nanoemulsion systems for topical ocular therapeutics can overcome the problem of multiple daily doses of traditional ocular therapy and improve patient compliance. To date, increasing interest surrounds nanoformulation studies, and the growing literature in this field is causing a great shift in the management of eye diseases, with the creation of successful products on the market and in clinical trials.

\section{ACKNOWLEDGEMENTS}

The authors are grateful to the College of Pharmacy, University of Mosul, Mosul, Iraq, for their support in this research.

Conflicts of interest: No conflict of interest was declared by the authors. The authors alone are responsible for the content and writing of this article

\section{REFERENCES}

1. Bucolo C, Drago F, Salomone S. Ocular drug delivery: a clue from nanotechnology. Front Pharmacol. 2012;3:1-3.

2. Al-bazzaz FY, Al-kotaji M. Ophthalmic in-situ sustained gel of ciprofloxacin, preparation and evaluation study. Int J Appl Pharm. 2018;10:153-161.

3. Ammar HO, Salama HA, Ghorab M, Mahmoud AA. Nanoemulsion as a potential ophthalmic delivery system for dorzolamide hydrochloride. AAPS PharmSciTech. 2009;10:808-819.

4. Kumari A, Sharma PK, Garg VK, Garg G. Ocular inserts: advancement in therapy of eye diseases. J Adv Pharm Technol Res. 2010;1:291-296.

5. Lallemand F, Daull P, Benita S, Buggage R, Garrigue JS. Successfully Improving Ocular Drug Delivery Using the Cationic Nanoemulsion, Novasorb. J Drug Deliv. 2012;2012:604204

6. Shah J, Nair A, Jacob S, Patel R, Shah H, Shehata T, Morsy M. Nanoemulsion based vehicle for effective ocular delivery of moxifloxacin using experimental design and pharmacokinetic study in rabbits. Pharmaceutics. 2019;11:230.

7. SCCS. "Guidance on the safety assessment of nanomaterials in cosmetics"(2012). Avaialable from: https://ec.europa.eu/newsroom/ sante/items/661871

8. Yen CC, Chen YC, Wu MT, Wang CC, Wu YT. Nanoemulsion as a strategy for improving the oral bioavailability and antiinflammatory activity of andrographolide. Int J Nanomedicine. 2018;13:669-680.

9. Patel A, Cholkar K, Agrahari V, Mitra AK. Ocular drug delivery systems: An overview. World J Pharmacol. 2013;2:47-64

10. Huang D, Chen YS, Rupenthal ID. Overcoming ocular drug delivery barriers through the use of physical forces. Adv Drug Deliv Rev. 2018;126:96-112.

11. Gaudana R, Ananthula HK, Parenky A, Mitra AK. Ocular drug delivery. AAPS J. 2010;12:348-360.
12. Suri R, Beg S, Kohli K. Target strategies for drug delivery bypassing ocular barriers. J Drug Deliv Sci Technol. 2020:55:101389.

13. Singh V, Ahmad R, Heming $T$. The challenges of ophthalmic drug delivery: a review. Int J Drug Discov. 2011;3:56-62.

14. Agban Y, Thakur SS, Mugisho OO, Rupenthal ID. Depot formulations to sustain periocular drug delivery to the posterior eye segment. Drug Discov Today. 2019;24:1458-1469.

15. DeGorter MK, Xia CQ, Yang JJ, Kim RB. Drug transporters in drug efficacy and toxicity. Annu Rev Pharmacol Toxicol. 2012;52:249-273.

16. Ruponen M, Urtti A. Undefined role of mucus as a barrier in ocular drug delivery. Eur J Pharm Biopharm. 2015;96:442-446.

17. D'Emanuele A, Jevprasesphant R, Penny J, Attwood D. The use of a dendrimer-propranolol prodrug to bypass efflux transporters and enhance oral bioavailability. J Control Release. 2004; 95:447-453.

18. Parveen S, Misra R, Sahoo SK. Nanoparticles: a boon to drug delivery, therapeutics, diagnostics and imaging. Nanomedicine. 2012;8:147-166.

19. Zdziennicka A, Krawczyk J, Szymczyk K, Jańczuk B. Macroscopic and microscopic properties of some surfactants and biosurfactants. Int $J$ Molecular Sci. 2018;19:1934.

20. Čalija B. Microsized and nanosized carriers for nonsteroidal antiinflammatory drugs: formulation challenges and potential benefits. Belgrade: Academic Press; 2017.

21. Jaiswal M, Dudhe R, Sharma PK. Nanoemulsion: an advanced mode of drug delivery system. 3 Biotech. 2015;5:123.

22. Delmas T, Piraux H, Couffin AC, Texier I, Vinet F, Poulin P, Cates ME, Bibette J. How to prepare and stabilize very small nanoemulsions. Langmuir. 2011;27:1683-1692.

23. Park H, Han DW, Kim JW. Highly stable phase change material emulsions fabricated by interfacial assembly of amphiphilic block copolymers during phase inversion. Langmuir. 2015;31:2649-2654.

24. Ako-Adounvo AM, Nagarwal RC, Oliveira L, Boddu SHS, Wang XS, Dey S, Karla P. Recent Patents on ophthalmic nanoformulations and therapeutic implications. Recent Pat Drug Deliv Formul. 2014;8:193-201.

25. Subrizi A, del Amo EM, Korzhakov-Vlakh V, Tennikova T, Ruponen M, Urtti A. Design principles of ocular drug delivery systems: importance of drug payload, release rate, and material properties. Drug Discov Today. 2019;24:1446-1457.

26. Carli F, Baronian M, Schmid R, Chiellini E, inventors; AZAD Pharma AG, assignee. Ophthalmic oil-in-water emulsions containing prostaglandins. United States patent application. 2013; US 13/804,794.

27. Toris CB. Pharmacotherapies for glaucoma. Curr Mol Med. 2010;10:824840.

28. Khan W, Aldouby YH, Avramoff A, Domb AJ. Cyclosporin nanosphere formulation for ophthalmic administration. Int J Pharm. 2012;437:275276.

29. Benita S, Elbaz E, inventors; Yissum Research Development Co of Hebrew University, assignee. Oil-in-water emulsions of positively charged particles. United States patent US 6,007,826. 1999 Dec 28. Available from: https://patents.justia.com/assignee/yisum-researchdevelopment-company-of-the-hebrew-university-of-jerusalem

30. Wang B, Tian H, Xiang D. Stabilizing the oil-in-water emulsions using the mixtures of dendrobium officinale polysaccharides and gum arabic or propylene glycol alginate. Molecules. 2020;25:759. 
31. Gupta A, Eral HB, Hatton TA, Doyle PS. Nanoemulsions: formation, properties and applications. Soft Matter. 2016;12:2826-2841.

32. Tadros TF. Emulsion formation, stability, and rheology. Emulsion formation and stability. 2013;1:1-75.

33. Qiu $H$, Chen $X$, Wei X, Liang J, Zhou D, Wang L. The emulsifying properties of hydrogenated rosin xylitol ester as a biomass surfactant for food: effect of ph and salts. Molecules. 2020;25:302.

34. Jaiswal M, Dudhe R, Sharma PK. Nanoemulsion: an advanced mode of drug delivery system. 3 Biotech. 2015;5:123.

35. Shakeel F, Baboota S, Ahuja A, Ali J, Aqil M, Shafiq S. Nanoemulsions as vehicles for transdermal delivery of aceclofenac. AAPS PharmSciTech. 2007;8:E104.

36. Nikam TH, Patil MP, Patil SS, Vadnere GP, Lodhi S. Nanoemulsion: a brief review on development and application in parenteral drug delivery. Adv Pharm J. 2018;3:43-54.

37. Sharma N, Mishra S, Sharma S, Deshpande RD, Sharma RK. Preparation and optimization of nanoemulsions for targeting drug delivery. Int J Drug Dev Res. 2013;5:37-48.

38. Chávez-Zamudio R, Ochoa-Flores AA, Soto-Rodríguez I, Garcia-Varela R, García HS. Preparation, characterization and bioavailability by oral administration of $\mathrm{O} / \mathrm{W}$ curcumin nanoemulsions stabilized with lysophosphatidylcholine. Food Funct. 2017;8:3346-3354.

39. Zhang J, Liu Z, Tao C, Lin X, Zhang M, Zeng L, Chen X, Song H. Cationic nanoemulsions with prolonged retention time as promising carriers for ophthalmic delivery of tacrolimus. Eur J Pharm Sci. 2020;144:105229.

40. Dukovski BJ, Juretić M, Bračko D, Randjelović D, Savić S, Moral MC, Diebold Y, Filipović-Grčić J, Pepić I, Lovrić J. Functional ibuprofenloaded cationic nanoemulsion: Development and optimization for dry eye disease treatment. Int J Pharm. 2020;576:118979.

41. Kumar M, Bishnoi RS, Shukla AK, Jain CP. Techniques for Formulation of Nanoemulsion Drug Delivery System: A Review. Prev Nutr Food Sci. 2019;24:225-234.

42. Kotta S, Khan AW, Ansari SH, Sharma RK, Ali J. Formulation of nanoemulsion: a comparison between phase inversion composition method and high-pressure homogenization method. Drug Deliv. 2015;22:455-466.

43. Henostroza MA, Melo KJ, Yukuyama MN, Löbenberg R, Bou-Chacra NA. Cationic rifampicin nanoemulsion for the treatment of ocular tuberculosis. Colloids Surf A Physicochem Eng. 2020;597:124755.

44. Chime SA, Kenechukwu FC, Attama AA. Nanoemulsions-advances in formulation, characterization and applications in drug delivery. Intechopen: London; 2014.

45. Frank SG. Emulsions: Theory and Practice. In: Becher P, Wilmington, $D E$, eds. Partnership with American Chemical Society. ( $3^{\text {rd }}$ ed). Oxford: Oxford University Press; 2001.

46. Hussain A, Altamimi MA, Alshehri S, Imam SS, Shakeel F, Singh SK. Novel approach for transdermal delivery of rifampicin to induce synergistic antimycobacterial effects against cutaneous and systemic tuberculosis using a cationic nanoemulsion gel. Int J Nanomedicine. 2020;15:1073.

47. Kulkarni SK. Nanotechnology: principles and practices. Switzerland: Springer; 2014.

48. Daull P, Feraille L, Elena PP, Garrigue JS. Comparison of the antiinflammatory effects of artificial tears in a rat model of corneal scraping. J Ocul Pharmacol Ther. 2016;32:109-118.
49. Dell SJ, Gaster RN, Barbarino SC, Cunningham DN. Prospective evaluation of intense pulsed light and meibomian gland expression efficacy on relieving signs and symptoms of dry eye disease due to meibomian gland dysfunction. Clin Ophthalmol. 2017;11:817-827.

50. Daull P, Lallemand F, Garrigue JS. Benefits of cetalkonium chloride cationic oil-in-water nanoemulsions for topical ophthalmic drug delivery. J Pharm Pharmacol. 2014;66:531-541.

51. Campbell PI. Toxicity of some charged lipids used in liposome preparations. Cytobios. 1983;37:21-26.

52. Manosroi A, Podjanasoonthon K, Manosroi J. Development of novel topical tranexamic acid liposome formulations. Int J Pharm. 2002;235:6170.

53. Draz MS, Fang BA, Zhang P, Hu Z, Gu S, Weng KC, Gray JW, Chen FF. Nanoparticle-Mediated Systemic Delivery of siRNA for Treatment of Cancers and Viral Infections. Theranostics. 2014;4:872-892.

54. Wu TH, Craven A, Tran T, Tran K, So K, Levi DM, Li RW. Enhancing coarse-to-fine stereo vision by perceptual learning: An asymmetric transfer across spatial frequency spectrum. Invest Ophthalmol Vis Sci. 2014:55:751.

55. Liu DX, Zhao XT, Liang W, Li JW. The stability and breakage of oil-in-water from polymer flooding produced water. Pet Sci Technol. 2013;31:20822088.

56. Patel N, Nakrani H, Raval M, Sheth N. Development of loteprednol etabonate-loaded cationic nanoemulsified in-situ ophthalmic gel for sustained delivery and enhanced ocular bioavailability. Drug Deliv. 2016;23:3712-3723.

57. Gurpreet K, Singh SK. Review of nanoemulsion formulation and characterization techniques. Indian J Pharm Sci. 2018;80:781-789.

58. Mahran A, Ismail S, Allam AA. Development of Triamcinolone AcetonideLoaded Microemulsion as a Prospective Ophthalmic Delivery System for Treatment of Uveitis: In Vitro and In Vivo Evaluation. Pharmaceutics. 2021;13:444.

59. Salimi A. Preparation and evaluation of celecoxib nanoemulsion for ocular drug delivery. Asian J Pharm. 2017;11:543-550.

60. Mahboobian MM, Foroutan SM, Aboofazeli R. Brinzolamide-loaded nanoemulsions: in vitro release evaluation. Iran J Pharm Sci. 2016;12:7593.

61. Lallemand F, Schmitt M, Bourges JL, Gurny R, Benita S, Garrigue JS. Cyclosporine a delivery to the eye: a comprehensive review of academic and industrial efforts. Eur J Pharm Biopharm. 2017;117:14-28.

62. Sharif HR, Sharif MK, Zhong F. Preparation, characterization and rheological properties of vitamin E enriched nanoemulsion. Pak J Food Sci. 2017;27:7-14.

63. Sarı ES, Koç R, Yazıcı A, Şahin G, Çakmak H, Kocatürk T, SS Ermiş. Tear osmolarity, break-up time and schirmer's scores in parkinson's disease. Turk J Ophthalmol. 2015;45:142.

64. Gallarate M, Chirio D, Bussano R, Peira E, Battaglia L, Baratta F, Trotta $\mathrm{M}$. Development of $\mathrm{O} / \mathrm{W}$ nanoemulsions for ophthalmic administration of timolol. Int J Pharm. 2013;440:126-134.

65. Khan NU, Ali A, Khan H, Khan ZU, Ahmed Z. Stability Studies and Characterization of Glutathione-Loaded Nanoemulsion. Journal of cosmetic science. 2018;69:257-267.

66. Gupta A, Narsimhan V, Hatton TA, Doyle PS. Kinetics of the change in droplet size during nanoemulsion formation. Langmuir. 2016;32:1155111559. 
67. Al-Omari NA, Butrus NH. Preparation, characterization and cytotoxic evaluation of novel au(iii) complexes of thioglycolate and 2-mercaptoglycolate ligands. Iraqi J Pharm Sci. 2013;13:28-40.

68. Rao R, Upadhyay SC, Singh MK. Nanoemulsion in ophthalmics: a newer paradigm for sustained drug delivery and bioavailability enhancement in ophthalmic manifestations. Int J Pharm Sci Rev Res. 2018;50:18-24.
69. Meng T, Kulkarni V, Simmers R, Brar V, Xu Q. Therapeutic implications of nanomedicine for ocular drug delivery. Drug Discov Today. 2019;24:15241538. 